\title{
Entrevista a Natalio R. Botana: una mirada sobre la gobernabilidad democrática y los derechos humanos en América Latina
}

Este comentario, junto a los documentos que analiza, está disponible en www.anuariocdh.uchile.cl

\author{
Por Silvana Lauzán*
}

\begin{abstract}
Matalio R. Botana nació en Buenos Aires. Se doctoró en Ciencias Políticas y Sociales en la Universidad de Lovaina. Miembro de la Academia Nacional de Ciencias Morales y de la Academia Nacional de la Historia. Entre sus libros publicados se encuentran La República vacilante, El siglo de la libertad y el miedo, De la república posible a la república verdadera, Sarmiento: una aventura republicana (con Ezequiel Gallo), Diálogos con la historia y la política (con Félix Luna), El orden conservador, Poder y hegemonía, entre otros. Recibió el premio Konex de Platino en ensayo político en 1994 y 2004. Es columnista del diario La Nación y miembro fundador del Círculo de Montevideo que preside Julio María Sanguinetti. Dictó cursos y seminarios en diversas universidades americanas y europeas. En 1979 obtuvo la Beca Guggenheim y en 1995 el premio Consagración Nacional en Historia y Ciencias Sociales. Ha sido Visiting Fellow en el St. Antony's College de la Universidad de Oxford y Profesor Visitante en el Instituto Universitario José Ortega y Gasset de la Universidad Complutense de Madrid. Actualmente es profesor emérito en la Universidad Torcuato Di Tella.
\end{abstract}

Buenos Aires, 20 de marzo 2009

Silvana Lauzán: La Convención Americana se aprobó en el año 1969. Teniendo en cuenta todos los acontecimientos ocurridos en la región a lo largo de estos años, ¿ usted cree que hay motivos para celebrar el 40 aniversario de la firma de la convención?

Natalio Botana: Las celebraciones para un politólogo ocupado de la historia, como es mi caso, siempre tienen matices. Creo que si algo podemos celebrar, es que en el año 1969 la situación de América Latina era una situación traumática desde el punto de vista político y de los derechos humanos. En ese entonces existían regiones en guerra civil, represiones feroces por parte de los gobiernos dictatoriales o semidictatoriales que procuraban contener el afán revolucionario, en fin, gobiernos de carácter autoritario como se los llamó en la política comparada de aquel entonces. Como dije en uno de mis libros, El siglo de la libertad y el miedo ${ }^{1}$, eran sin embargo gobiernos

* Directora del Programa de Derechos Humanos y Democracia, del Centro de Derechos Humanos de la Universidad de Chile. Licenciada en Ciencia Política y Gobierno de la Universidad de Torcuato Di Tella, Argentina; Máster en Sociología de la London School of Economics and Political Science, Inglaterra, y diplomada en Derechos Humanos y Procesos de Democratización del Centro de Derechos Humanos de la Facultad de Derecho de la Universidad de Chile. Ha trabajado como coordinadora de proyectos en organizaciones de la sociedad civil en Argentina y Chile (Centro de Estudios Legales y Sociales/CELS, Poder Ciudadano/Transparencia Internacional, Cippec, Corporación Participa). Se ha desempeñado como profesora asistente en la materia Teoría del Estado en la Universidad Di Tella. Ha investigado y coordinado proyectos vinculados a la promoción de los derechos humanos, reformas del Estado en América Latina (transparencia, control social y acceso a la información pública), y participación ciudadana. Es autora del "Manual de Monitoreo de Instituciones públicas: el caso del Senado Argentino" publicado por Transparencia Internacional, coautora del "Manual de Incidencia de la Sociedad Civil en el Poder Legislativo", autora de "La regulación del secreto", entre otros. slauzan@derecho.uchile.cl

1 Botana, N., El siglo de la libertad y el miedo, Editorial Sudamericana, Buenos Aires, 2001 (tercera edición). 
autoritarios con momentos totalitarios muy fuertes en relación con aquellos sectores que eran reprimidos. Si vemos la situación hoy, y obviamente aquí ha mediado la caída del muro de Berlín a fines de la década del ochenta, es claro que para América Latina, para la región entera, el principio de legitimidad que la rige y orienta son las declaraciones de derechos humanos a través de sus diferentes documentos. Eso conforma un horizonte de legitimidad, una propuesta de la buena vida en sociedad, que efectivamente sirve para orientar la acción y como parámetro para decir lo que está bien y lo que está mal. En ese sentido, mi impresión es que a 40 años de esta Convención, en América Latina no hay un conflicto de principios de legitimidad opuestos, como pudo haber sido precisamente el gran conflicto en los 60 y 70 con aquella ambiciosa presencia del proyecto de la revolución encarnado en Cuba, como un proyecto que debía expandirse por todo el continente como decía el Che Guevara, con la cordillera de los Andes como columna vertebral. Ahí ha habido un avance importantísimo, porque en la larga perspectiva de la historia no hay duda que las cosas se complican extraordinariamente cuando hay un conflicto profundo entre principios de legitimidad. Ese conflicto hoy ha desaparecido, y esto sería la razón fundamental para celebrar. $\mathrm{Y}$ antes que me pregunte le digo esto: el problema de fondo cuando existe un principio de legitimidad en tanto principio acatado son las dificultades que existen en la misma palabra principio, porque principio es un fundamento y al mismo tiempo es el punto de partida de un itinerario, $y$ el itinerario que plantea el horizonte de los derechos humanos es la traducción de esos derechos en instituciones efectivas y aquí las contradicciones son enormes y muy serias.

\section{SL: Vayamos a ese punto. ¿Cómo cree que han podido ser resueltas, en la región, las tensiones que se generan propias de la promoción de los derechos humanos?}

NB: En mis últimos escritos inspirados en el pensamiento de José Luis Romero, un gran historiador argentino, planteo que habría dos visiones de la historia. Hay una visión horizontal de la historia entendida como un proceso, en procura de realzar determinadas metas. Desde este punto de vista horizontal creo que ha habido avances importantes en relación, por ejemplo, con los derechos humanos que habían sido conculcados por razones políticas e ideológicas. Hoy, en América Latina se está juzgando al pasado, no sólo en la Argentina sino también parecería que las cosas avanzarían en Uruguay, y ha habido avances muy importantes en Chile. Ahora, si usted corta esta visión horizontal de la historia con una visión vertical, buscando interrogar a los actores ignorados y sumergidos, como pretendía interrogar Domingo Faustino Sarmiento ${ }^{2}$ en el Facundo, ahí nuevamente las cosas se complican extraordinariamente. Esto ocurre porque el problema es que el ámbito de aplicación de los derechos humanos en América Latina, en algunos casos más que en otros, en algunas regiones más que en otras, está quebrado.

\section{$S L:$ ¿Qué significa que está quebrado?}

NB: Significa que existen enormes sectores de la población marginados y excluidos que no pueden efectivamente demandar sus derechos, y hacerlos efectivos en términos preventivos. Estamos entrando a los bicentenarios ahora pero desde los orígenes mismos de nuestras Repúblicas se ha planteado la gran demora histórica referida al establecimiento de un estado de derecho fundado en la seguridad y en la administración universal de la justicia. Eso es muy ostensible hoy en la Argentina, y ni qué decir de la situación actual en América Central, salvo tal vez la excepción de Costa Rica. Hay un hecho que me impactó muchísimo, y que recuperé en una reciente conferencia

2 Domingo Faustino Sarmiento (1811-1888) fue un político, pedagogo, escritor, docente, periodista, estadista y militar argentino; gobernador de la Provincia de San Juan entre 1862 y 1864 y Presidente de la República Argentina entre 1868 y 1874. Se destacó por su laboriosa lucha en favor de la educación pública. 
en México. Se interrogaba a un miembro de una mara, en Guatemala, y este muchacho decía que la mara era para él el equivalente de la familia y de la seguridad, y a su vez desde la mara (él no lo decía, lo digo yo) estaba creando condiciones de inseguridad cada vez más pronunciadas. Con esto quiero decir que, y eso nos lleva inevitablemente a los temas de gobernabilidad democrática, cuando se han acentuando los niveles de desigualdad como lo han hecho en estos 40 años, la vigencia de los derechos humanos adquiere una connotación muy especial. Retomando el punto sobre los sectores de la población marginados y excluidos, mi preocupación en este momento es la mujer sumergida, la mujer explotada. No sólo explotada en razón de la exclusión y la marginalidad, sino explotada en el seno de las mismas familias o agrupamientos familiares o como quiera Ilamárselos. Ahí veo un problema más serio y explosivo de América Latina, porque es un problema de confrontación de realidades con principios deseables. Evidentemente cuando existe esa confrontación, los conflictos pueden ser muy serios, y por eso el gran desafío que se le plantea a la gobernabilidad latinoamericana en este momento no es tanto llevar adelante una política de libertad, sino llevar adelante una política de igualdad conjugada con una política de libertad. Allí justamente estamos muy rezagados y creo que se va a rezagar más la cosa debido al impacto que va a tener la crisis económica internacional que ha estallado el año pasado.

\section{SL: ¿Cree que las diferencias ideológicas entre los gobiernos de la región aportan matices in- teresantes a la hora de analizar en qué país se ha logrado mayor avance en el respeto por los derechos humanos?}

NB: Sí, pero creo que el problema fundamental en este momento no son tanto las diferencias ideológicas. Como ejemplo tomemos el caso de Venezuela, que es tan polémico. Chávez es un hombre tan combativo, y uno podría imaginar por su retórica que debería conducir a un ascenso de Venezuela, o a un desarrollo positivo en el plano de esta historia horizontal que he planteado, ir abarcando cada vez más derechos. Pero por otro lado, si uno ve los indicadores sociológicos, en Venezuela ha aumentado la pobreza y la inseguridad. Entonces el punto crucial es ¿dónde están los derechos humanos cuando en determinadas regiones urbanas de nuestras democracias impera un clima de inseguridad y de ausencia del Estado? Creo que lo que está pasando en México tiene que Ilamarnos la atención. Este país es de una importancia capital en América Latina, y hay problemas de una gravedad insospechada. Yo no quiero caer en los extremos de muchos analistas que hablan de que México puede ser un Estado fallido, desde ningún punto de vista. El país tiene reservas muy grandes, pero a la vez tiene un desafío enorme que es enfrentar la violencia del narcotráfico. Del mismo modo me preocupa lo que ocurre en Colombia, porque lo interesante allí es que el problema del control territorial en manos de las FARC no ha sido superado a pesar de todos los aparentes éxitos que dice tener el Presidente Uribe. Este es un gran problema de América Latina.

\section{SL: ¿Se refiere a la incapacidad o ausencia del Estado en ciertos ámbitos?}

NB: Claro, este contraste entre las normas, los principios, las convenciones y los derechos escritos que nos rigen y la realidad, la desigualdad basada -entre otras cosas- en la ausencia del Estado. Ese es un gran desafío de América Latina, por ejemplo, cómo organizar buenas policías. No se ha trabajado suficientemente en el hecho de que una República necesita una excelente policía civil capaz de prevenir el delito; no hemos trabajado debidamente todavía en todas las grandes reformas judiciales, o deberíamos profundizar mucho más la necesidad de reformar los códigos de procedimientos más que los códigos penales. Hay estudios pendientes todavía que son importantísimos: los Códigos de Procedimiento Penal tienen la astucia de demorar la sentencia, ¿y quiénes acceden a la demora de la sentencia? Ahí queda claramente planteado el problema de 
la desigualdad: acceden los que tiene más recursos para contratar abogados, y no acceden los que tienen menos recursos para hacerlo. A eso se suma un problema muy serio, que está muy en debate en América Latina, que es la mayor permisividad que tienen las sentencias, y sobre todo las detenciones provisorias.

SL: ¿Esos son los temas de una agenda de trabajo de gobernabilidad democrática en la región? ¿Las reformas de la justicia y la seguridad?

NB: Sí, yo creo que esto es prioritario. Estoy preocupado con estos dos temas en relación al Estado. Que la población más abandonada y más excluida en nuestras Repúblicas vea a las policías como un enemigo nos ubica en el peor nivel del Estado.

\section{SL: Claro, lo que es terrible es que en muchos casos sea una percepción justificada.}

NB: Pero por supuesto, desde luego que sí.

SL: Volviendo a la discusión sobre la gobernabilidad democrática en la región, algo que se ha analizado en alguna medida tiene que ver con el fenómeno de los "gobiernos interrumpidos". Muchos ejemplos de los últimos años en la región muestran que se logró institucionalizar la democracia electoral, pero en ocasiones las administraciones han tenido serias dificultades para completar sus mandatos. ¿Qué reflexión le suscitan estos hechos? ¿En qué medida cree usted que estas crisis tienen que ver con una crisis del Estado, del capitalismo, con una crisis del sistema representativo tradicional?

NB: Bueno, tiene mucho que ver el Estado. Cierto nivel del problema ha sido tratado y se cuenta con muchísimos estudios sobre la democracia electoral, la cual es el gran insumo de la democracia latinoamericana. Frente a eso retomo una muy breve reflexión de Ricardo Lagos en un texto perteneciente a un libro que, con otros autores, escribimos para el estudio que hizo el Programa de Naciones Unidas para el Desarrollo sobre la democracia en América Latina. Yo suelo referirme a la democracia institucional y Lagos dice que la democracia institucional es la bisagra que existe entre la democracia electoral y la democracia de ciudadanas y ciudadanos a la cual aspiramos. Esa bisagra, la democracia institucional, y estoy hablando en general porque hay excepciones importantes, está oxidada. La bisagra está oxidada, porque las instituciones no responden. Esto ya viene siendo analizado desde la época en que se acordó la Convención de Derechos Humanos, y obedece a un fenómeno histórico de América Latina que se lo llamó la revolución de las expectativas, y que es un tema central de la teoría democrática. La revolución de las expectativas es un proceso fácil de describir: si el pueblo exige, si las demandas son crecientes, las instituciones capaces de responder también deberían crecer y desarrollarse de manera equivalente. Existe una corriente que ha analizado muy bien los problemas fiscales desde el punto de vista de la Ciencia Política, no desde la Economía, y muestra una cosa elemental y es que los derechos, para ser efectivos, cuestan dinero. Si no existe una policía bien equipada, educada y al servicio de los derechos humanos, si no hay una justicia eficaz, bueno, entonces existen derechos virtuales pero no derechos efectivamente arraigados. Esto quiere decir que la otra parte de los derechos son las obligaciones fiscales y basadas en impuestos directos progresivos que deberían existir en nuestras democracias, y en este aspecto el avance es aún es muy lento, ha habido países que han avanzado más que otros. Brasil es uno de ellos. Esto tiene que ver con el estado de nuestras economías, porque en el caso de economías como las de América Central y el Caribe, que viven fundamentalmente de las remesas que los inmigrantes mandan del exterior para sostener a sus familias, el problema es muy serio. Usted habló de la crisis del capitalismo, bueno, yo hablo del desarrollo de nuestras economías capaces de producir la base, la materia, para instalar a partir 
de ello una ciudadanía fiscal efectiva. Este juego entre derechos y obligaciones, aquel concepto de obligación política que Norberto Bobbio desarrolló con tanta agudeza, es un tema para meditar en América Latina porque a veces tenemos la sensación de que este es el continente de los derechos, pero creo que es el continente de los derechos virtuales que no están respaldados por la obligación fiscal suficiente para hacer que puedan traducirse en instituciones eficientes y de carácter universal, en el sentido que abarquen a toda la población de un territorio determinado. Ahí hay uno de los problemas de gobernabilidad más interesantes; parte del conflicto fiscal que se está viviendo hoy en la Argentina viene de mucho antes, y debido fundamentalmente a que este país funciona con criterios fiscales absurdos y obsoletos.

\section{SL: ¿A quién le cabe la responsabilidad de promover estos cambios?}

NB: "No taxation without representation"3. Le cabe la responsabilidad a nuestros Congresos. Si hay una cosa que explica el nacimiento del Parlamento moderno es precisamente la política fiscal, para eso están los representantes. Ahí el terreno que todavía debemos atravesar es extenso, hay mucho que hacer, no sólo en la extensión del imperio de las obligaciones fiscales sino la prudencia necesaria para no producir a través de esos sistemas fiscales inequidades absurdas en virtud de las cuales, por ejemplo, los únicos que sostienen al Estado con el pago de impuestos directos son los que están en relación de dependencia. Y aquellos que no están en relación de dependencia entonces pueden eludir y evadir, ¿por qué se evade? Porque como se viene diciendo desde el siglo XVIII, los organismos del Estado están mal organizados. El Estado es un mecanismo de control sujeto a la legalidad y esto evidentemente tiene grandes agujeros.

\section{SL: ¿Usted cree que el problema es de organización?}

NB: Fundamentalmente creo que es un problema de organización y de control de la corrupción, del control intraestatal de la corrupción que es uno de los desafíos más grandes que tiene la gobernabilidad en América Latina en este momento. Es el desafío del narcotráfico, entre otras cosas, es decir, la penetración de las fuerzas del crimen organizado fuera del Estado en su origen, dentro del mismo Estado. Porque yendo al ejemplo más elemental, si yo tengo una inspección fiscal y arreglo esa inspección fiscal con una coima, entonces quiere decir que el Estado no funciona.

\section{SL: ¿Cuáles son, en su opinión, los parámetros para medir el éxito de la gobernabilidad? Porque volviendo a la pregunta anterior, una cosa es que no haya quiebres institucionales y otra cosa es que el sistema político tenga la capacidad efectiva de responder a demandas sociales sustantivas.}

NB: Me parece muy interesante tomar el caso de Lula, porque los problemas de gobernabilidad se resuelven con mucha dificultad gracias a la acumulación virtuosa de creación institucional, y uno puede pensar positivamente sobre la propuesta de Lula de Hambre Cero, porque efectivamente se puede llegar a la conclusión de que está funcionando. La pregunta es ¿por qué funciona? Bueno, no funciona por un acto de voluntarismo que uno puede registrar como si tuviera en sus manos una cámara fotográfica. En primer lugar, Brasil tiene una tradición estatal muy fuerte, en segundo lugar, -y de aquí el concepto de acumulación- los dos períodos de Lula suceden a dos períodos de Fernando Henrique Cardoso, es decir, que esto está creando ya una acumulación virtuosa de experiencias de 16 años. Las transformaciones de Lula con Hambre Cero tienen a su favor el

\footnotetext{
Principio de la cultura liberal anglosajona, que comenzó como eslogan en el período 1763-1776, y resume un reclamo por parte de los colonos británicos en Estados Unidos que consideraban una violación de sus derechos como ingleses el no estar representados directamente en el Parlamento Británico, y en consecuencia, consideraban inconstitucional que se les cobraran impuestos.
} 
resorte de las transformaciones fiscales que se produjeron durante la administración de Fernando Henrique Cardoso. Todo lo contrario de lo que ocurre en Argentina, donde hasta ahora no ha ocurrido la acumulación de experiencias, daría la impresión que en la Argentina todo gobierno cree ingenuamente que inicia una experiencia sin relación con las anteriores, entonces en lugar de acumulación de experiencias hay exclusión de experiencias. Tal vez en su nivel más radicalizado eso se puede observar en la experiencia de Venezuela también.

\section{SL: ¿Cuáles serían ejemplos de países en la región que usted considera que han logrado desa- rrollarse inclusivamente $y$ ser gobernables?}

NB: Bueno, ninguno ha logrado desarrollarse inclusivamente porque Brasil, aunque lo hemos citado como un caso interesante de gobernabilidad, tiene problemas de exclusión y de marginalidad muy severos. Por cierto constituyen un ejemplo los dos pequeños países de los cuales se hablaba como modelos de "pequeñas democracias" cuando se firmó la Convención, Uruguay y Costa Rica. Hay un fenómeno interesante en Uruguay. Desde el punto de vista de los indicadores de la integración social, la sociedad uruguaya tiene procesos, no diría de exclusión, pero de marginación y sobre todo de expulsión de la población. Constantemente hay un porcentaje importante de la población uruguaya que se va, que busca el destino de la inmigración. En Chile, por ejemplo, han existido unas "políticas tendientes a superar las desigualdades" -así las Ilamo siguiendo una idea lejana de Giovanni Sartori-, que es el gran desafío de la política democrática. La política de la libertad es una política negativa, en el sentido de que una vez que estamos protegidos en nuestro ámbito íntimo, y en nuestro ámbito de ciudadanas y ciudadanos, decimos lo que pensamos. Pero el desafío más grande es cómo hacer políticas de igualdad o de libertad positiva, como las llamaba Isaiah Berlín. Creo que las políticas de este tipo son políticas conjuntas. Por ejemplo, es imposible imaginar una política que logre ir superando los niveles de desigualdad social actuales, sin pensar y concebir una política educativa como el resorte fundamental de la movilidad social. Uno de los parámetros más interesantes para analizar las políticas en esta línea es hacer un ranking de América Latina, en el cual uno pueda medir qué resultados han tenido las políticas de reformas educativas. No le puedo dar ejemplos porque no soy un especialista en el tema, pero ahí veo un núcleo importantísimo. No hay que olvidar una cosa: Argentina entre la primera década del siglo XX y fines de la década del 60, tuvo los niveles de movilidad social, junto con Uruguay, más altos de América Latina. ¿Por qué los tuvo? Porque tenía una economía en expansión, en parte, pero además no existe ninguna duda de que el resorte de la aventura del ascenso fue el sistema educativo. Esto en América Latina tiene mucho que ver no sólo con las políticas que se puedan hacer desde el Estado porque, claro, la época en que Sarmiento imaginaba un sistema educativo para toda la población argentina no se le pasaba por la cabeza la presencia activa de sindicatos de la educación fuertes y muy bien organizados. Entonces lo que se impone es una política de concertación y una reorientación de los presupuestos, para llevar adelante una política masiva en materia educativa. Tenemos que pensar un Sarmiento colectivo para el siglo XXI.

El otro punto importante en relación con una gobernabilidad democrática con inclusión es analizar de cerca qué políticas de reforma urbana podemos implementar en nuestras megalópolis. Esto incluye transporte, poblaciones marginales, sistemas cloacales... Yo me pregunto si se está pensando la cuestión que plantean las megalópolis en América Latina, lo que dicho sea de paso, es una cuestión mundial. Carlos Fuentes recordaba que cuando nació en 1928, en México había algo así como 25 millones de habitantes y en Ciudad de México 2 millones; ahora hay en Ciudad de México 25 millones de habitantes. En la ciudad de San Pablo, en Brasil, hay 25 millones de habitantes aproximadamente. Las cuatro ciudades, Buenos Aires, incluyendo el conglomerado urbano, San Pablo, Ciudad de México y Río de Janeiro deben estar en torno 
a los 70 millones de habitantes. ¡Setenta millones, tendiendo a ser dos veces Argentina, no le digo cuántas veces Chile!

\section{SL: ¿Y qué es lo desafiante de gobernar esas megalópolis?}

NB: Todo es absolutamente desafiante allí y no se ha asumido ese reto. Porque lo que está pasando en América Latina es que esos Leviatanes, esas nuevas formas del Leviatán, están venciendo a los gobernantes de una manera paradójica porque, por un lado, no pueden con los índices de criminalidad, con la mala calidad de los servicios públicos, con los índices de indigencia. Pero por otro, (y la lección argentina es muy interesante al respecto) esas megalópolis ofrecen un reservorio de población marginal dependiente de la protección del Estado para desarrollar el clientelismo. Entonces el juego es doble, y se advierte que ese va a ser el gran reto del siglo XXI, más allá del mundo desarrollado que por supuesto sigue siendo un mundo minoritario dentro del planeta; este es un reto de carácter mundial y me satisface que las Naciones Unidas lo hayan tomado en sus manos, por lo menos exponiéndolo. Imagínese usted lo que son las megalópolis en África o las megalópolis en China. Es otra escala de la República.

\section{SL: Porque somos Repúblicas, aun con todos los déficits que tenemos...}

NB: Con todas las fallas que tenemos. Y es uno de los temas básicos que tuvo que encarar la teoría republicana desde sus orígenes mismos en la antigüedad: la escala humana de la República. La escala está marcada por nuestras megalópolis; y digo megalópolis en relación con la población, porque uno puede ver, por ejemplo, una ciudad en América Central y creer que no es tan grande en comparación con San Pablo, pero fíjese en la proporción que siempre es muy alta.

SL: En ese sentido existen fenómenos que son muy interesantes y que tienen que ver con los movimientos sociales que se han articulado o generado en las periferias de las grandes ciudades. Estos movimientos tienen una gran capacidad de articulación y demanda, con dinámicas de organización diferentes a las tradicionales de las organizaciones de la sociedad civil. Los movimientos tienen otro lenguaje y una propuesta que pareciera ir más allá del cambio social (en el sentido de búsqueda de cambio a través de movilidad social), para proponer un cambio societal, con otras reglas del juego, otras prácticas y relaciones entre actores, especialmente con las instituciones formales. ¿Cuál es su valoración de este fenómeno?

NB: Bueno, esa es la revancha de los huérfanos de Alexis de Tocqueville. Recuerde que los seguidores de Tocqueville con las teorías sobre el capital humano, trabajan sobre el supuesto del "asociacionismo" en sociedades con razonables niveles de ingreso, en un grado, digamos, normalizado. Dados esos niveles de ingreso la sociedad civil podría por consiguiente generar asociaciones u ONG's capaces de perfeccionar la democracia. Lo interesante del caso es que ahora el principio asociativo no está jugando entre nosotros dentro del nivel normalizado de las megalópolis, sino que lo está haciendo en el nivel que podríamos Ilamar "de los de afuera". Esos de afuera también se organizan, lo cual en principio es positivo, siempre y cuando pueda lograrse una simbiosis entre las instituciones informales que ellos están formando y las instituciones formales. Esas instituciones informales van a reformar o van a presionar a las instituciones formales, o de lo contrario, las instituciones formales tendrían que tener la apertura suficiente para entablar por lo menos una relación de diálogo con ellas. En Bolivia, por ejemplo -y hay grandes polémicas, lo sé-, están buscando aplicar para determinados niveles de administración de justicia, principios de justicia comunitaria que no estaban institucionalizados en el nivel formal de las instituciones. Eso puede ser una experiencia positiva siempre y cuando no actúen como principios contradictorios, pues, al plantear un conflicto de ese tipo, en general, se resuelve de modo excluyente, o una cosa 
o la otra. Pero cuidado porque también me refería a las maras y esa es otra forma de asociación; como la mafia es una forma de asociación, que evidentemente se puede definir como criminal. Eso demuestra que la gente aislada está buscando protegerse a sí misma.

\section{SL: Yo estaba pensando en nuevas formas de asociación que están construyendo nuevos modelos de hacer política también, de involucrarse con la política.}

NB: Eso está muy bien pero allí viene el gran debate que empieza en el siglo XIX. El proletariado, en la vieja teoría, estaba buscando nuevas formas de involucrarse en la política. ¿Esas nuevas formas van a renovar el sistema obsoleto de partidos políticos en muchos países? La respuesta que hubo a fines del siglo XIX, entre las dos guerras, y sobre todo en la posguerra de la Segunda Guerra Mundial, es que sí. Entonces se crearon nuevos partidos, como los llamó un viejo politólogo "de creación externa", los partidos socialdemócratas, los partidos de inspiración cristiana y demás, que llevaron esa nueva forma de hacer política a partir de intereses sociales a la esfera pública de las decisiones, es decir, a los parlamentos. Eso todavía no ha ocurrido en América Latina, en donde simplemente estamos viviendo el laboratorio en el primer nivel.

\section{SL: ¿Y cree que sería deseable que eso se desarrolle en aquella dirección?}

NB: No me cabe ninguna duda, si se tiene presente que lo fundamental para estas democracias es la mediación política, porque somos democracias representativas. Por consiguiente, una mediación social que no se traduce en mediación política puede hacer que las sociedades giren en rueda libre. Necesitamos mediaciones políticas y no veo todavía, en términos de asociación política, una institución capaz de reemplazar al partido político. Hay sustitutos, no cabe duda que los medios de comunicación muchas veces actúan como sustitutos de la política, pero llega un momento en el cual más allá de esa miríada de organizaciones sociales nuevas, alguien tiene que hacerse cargo, asumir la responsabilidad y responder en función de ella, porque se trata de una democracia, y eso lo debe hacer el partido político.

\section{SL: Si bien es algo que los partidos no han venido haciendo del todo bien...}

NB: Aquellos países que les va mejor son aquellos que históricamente han desarrollado un sistema de partidos. A países como Brasil, que no lo tenían y que lo han desarrollado, también les va mejor. Argentina, en ese sentido tiene un vacío importante que colmar.

SL: Respecto a los quiebres institucionales Juan Linz tenía la tesis de que los presidencialismos tienen una debilidad en comparación con los parlamentarismos, y es que carecen de instancias que permitan descomprimir las crisis políticas, evitando que el sistema se quiebre. ¿El parlamentarismo sería un mejor sistema para algunos países?

NB: No tengo una posición definida, porque me interesa seguir las evoluciones históricas y en América Latina hay una suerte de resistencia al parlamentarismo. Nos hemos casi empachado de reformas constitucionales, y esas reformas no han tomado un rumbo parlamentario, sino por el contrario, muchas han reforzado la hegemonía presidencialista. Haciendo política comparada con Europa, porque es útil usar como punto de comparación regímenes parlamentarios del tipo británico, o en la clave de la representación proporcional del doble voto de la República Federal de Alemania, es importante atender al hecho de que entre las dos guerras mundiales y la inmediata posguerra, el parlamentarismo fue muy inestable en Europa. Uno puede tomar como punto de referencia la Quinta República, que es el régimen de los últimos cuarenta años en Francia, pero para llegar allí hubo que atravesar las severas crisis de estabilidad de la Cuarta República. Entonces 
mi impresión es que el parlamentarismo no termina de arraigar. Por ejemplo, en Argentina, cuando se consolida el proceso constituyente del siglo XIX, la Constitución argentina de 1853-1860 tenía elementos parlamentarios más acentuados que la de Estados Unidos, en el sentido de que los ministros del Poder Ejecutivo podían ser interpelados por el Congreso, es decir, podían ser Ilamados a rendir cuentas. Para eso el Congreso Nacional tiene su banco dedicado a los ministros. La reforma constitucional de 1994 estableció la figura de jefe de gabinete, con la obligación de que concurra una vez por mes a rendir cuentas. En los grandes debates parlamentarios del siglo XIX y de principios del siglo XX, por ejemplo, los debates sobre la ley de educación común en la década del ochenta del siglo XIX, o los debates sobre ley Sáenz Peña en 1911-1912, el rol predominante lo desempeñaba el ministro del ramo. Los discursos de la reforma electoral de 1902 de Joaquín V. González y en el 1911 y 1912 de Indalecio Gómez, ambos Ministros del Interior, ya no se escuchan. Aun con la obligación constitucional de que el jefe de gabinete vaya a rendir cuentas, su presencia es poco menos que intrascendente. Es decir, aquí hay tendencias muy fuertes en América Latina a favor de la personalización presidencial, en algunos países mucho más acentuado que en otros. En los países del MERCOSUR, en cuanto a personalización del poder presidencial, los primeros puestos los ocupan holgadamente Argentina y Bolivia, y después más abajo, Brasil, Uruguay y Chile. Entonces en cuanto al régimen parlamentario hay un rico debate académico, pero me da la impresión de que ese debate no ha impregnado las costumbres políticas.

\section{SL: Pensando en el momento de la firma de la Convención al día de hoy, el rol de las Fuerzas Armadas ha cambiado en la región. ¿Qué opina al respecto?}

NB: El rol de las Fuerzas Armadas ha cambiado sustancialmente y para bien. Yo ni señalo el problema, aunque hay países que Ilegaron tarde a este plano deseable como Chile, porque hoy podemos decir que las FFAA están realmente subordinadas al poder civil. Eso no quita que, sobre todo en la política de seguridad en las megalópolis, muchas veces por falencia de las instituciones del Estado como jueces y policías, esa política se militarice.

\section{SL: ¿Por qué cree que se avanzó tan poco con los intentos por institucionalizar una política a nivel regional a través del MERCOSUR? ¿Cómo lo ve hacia delante, cree que esta, u otras insti- tuciones como el UNASUR, tienen posibilidades de desarrollarse más ampliamente, o están en un callejón sin salida?}

NB: Más que en un callejón sin salida yo creo que estamos en un pantano, porque de un callejón sin salida no se puede salir. América Latina se lanzó a los procesos de integración pensando en la experiencia europea. Dicha experiencia la viví en sus orígenes, mientras estudiaba en Europa a principios de la década del sesenta, cuando estaban en plena formación las instituciones del Mercado Común, después de la Comunidad Europea, y ahora de la Unión Europea. Lo que advertí en ese momento fue la transferencia de una experiencia institucional acumulada en el nivel nacional hacia las instituciones de la supranacionalidad. En Europa se pudo establecer el principio de la doble legalidad porque había una legalidad instituida muy fuerte. Durante los años 30 y 40 esa legalidad fue puesta al servicio de las ignominias más terribles que conoció el género humano, pero esa es otra historia, porque la tragedia de Alemania es que para hacer lo que hizo el nazismo necesitaba eficiencia burocrática. Esa legalidad instalada necesitaba otra orientación hacia fines políticos dignos, ser en suma depurada, pero, insisto, tenían esa legalidad. En América Latina no. Nuestras legalidades son mucho más frágiles y asincrónicas. En el MERCOSUR, por ejemplo, tenemos una legalidad más fuerte en Brasil que en la Argentina, en Chile más fuerte que en Brasil y Argentina, pero evidentemente no hemos logrado armar instituciones comunes. Eso se amortigua porque hay un gran intercambio entre presidentes y en alguna medida son capaces de establecer políticas conjuntas sobre todo en materia de política exterior de América Latina. 


\section{SL: Pero serían alianzas más circunstanciales}

NB: Existe una gran capacidad diplomática en el momento, aunque luego eso institucionalmente se apaga. Por supuesto, ha sido de una utilidad extraordinaria en algunas circunstancias. Pero, por ejemplo, en Europa la Comisión Europea fue desde los orígenes del mercado común el foco del poder ejecutivo; no hay nada equivalente en nuestra región y eso se debe a nuestra poca habilidad nacional para construir instituciones.

\section{SL: Por último ¿cómo ve el creciente proceso de apertura de Cuba?}

NB: Interesante. Recuerdo que hubo una discusión en Buenos Aires con un liberal dogmático, que estaba encantado con el bloqueo de Estados Unidos a Cuba en nombre de principios liberales. Con toda modestia se le apuntó que todos los autores fundadores de la tradición liberal del siglo XVII sostenían que había que abrir las fronteras, porque justamente lo que realmente morigera el nepotismo es el comercio. Quedó un poco desconcertado este escritor. Recién ahora con la administración de Barack Obama se reconoce que ha sido una política inconducente, que lo único que ha producido es más atraso en la relación con Cuba. Ahora creo que lo más importante para Cuba, al igual que para los países del Caribe y América Central, es el flujo libre y sin trabas de las remesas. Eso sería un bien inmenso porque la transformación de Cuba es de mediano si no de largo plazo. El plan que ellos se han fijado evidentemente es una transformación muy lenta, que tendría que empezar por el lado de la economía, de la sociedad civil, y eventualmente después combinar con la esfera política. Pero la lección de China, en este sentido, es ejemplar en el mal sentido de la palabra, porque no hay transformación política en ese país. Esto demuestra que la esfera política sigue teniendo autonomía, y no como sostenía Seymour Martin Lipset -entre otrosen la década del 60, que la transformación económica necesariamente produce la transformación política. Eso no es así y ahí hay un salto cualitativo sobre el cual reflexionar. 